\title{
Nurses towards End-of-Life Situations: Sympathy vs. Empathy
}

\author{
Jefferson Garcia Guerrero \\ Fakeeh College for Medical Sciences, Jeddah, Saudi Arabia \\ Email: jgguerrero@fakeeh.care, jgguerrero@fcms.edu.sa
}

How to cite this paper: Guerrero, J.G. (2019) Nurses towards End-of-Life Situations: Sympathy vs. Empathy. Open Journal of Nursing, 9, 278-293.

https://doi.org/10.4236/ojn.2019.93027

Received: February 3, 2019

Accepted: March 11, 2019

Published: March 14, 2019

Copyright $\odot 2019$ by author(s) and Scientific Research Publishing Inc. This work is licensed under the Creative Commons Attribution International License (CC BY 4.0).

http://creativecommons.org/licenses/by/4.0/

\begin{abstract}
Background: Nurses providing end-of-life care play an important role in providing support to both the patient and his/her family during one of their most difficult time. Patients in this stage do not only require physical care but emotional support as well. Aside from being a care provider, nurses should be able to utilize their knowledge in therapeutic communication in order for the patients and his/her family members to verbalize their feelings and concerns. Objective: The purpose of this study is to identify whether nurses project sympathy or empathy while providing end-of-life care. It also aims to determine their lived experiences while proving care at this stage. Methodology: This study utilized the mixed convergent parallel design wherein both the quantitative research and qualitative research were employed. Result and Discussion: A factor analysis was conducted on 12 items with maximum likelihood extraction method and oblique (Promax) rotation method. The Kaiser-Meyer-Olkin (KMO) measure verified the sampling adequacy for the analysis, $\mathrm{KMO}=0.792$ ("meritorious" according to Kaiser (1974)). Bartlett's Test of Sphericity $\left(\chi^{2}(66)=1007.294, \mathrm{p}<0.001\right)$ indicated that correlations among items were sufficiently large for factor analysis. The newly formed four-itemed factors were proven to be internally consistent (affective empathy $\alpha=0.881$, sympathy $\alpha=0.804$, and cognitive empathy $\alpha=0.728$ ). Correlations among the factors were $\mathrm{r}=0.315$ for affective empathy and sympathy, $\mathrm{r}$ $=0.295$ for sympathy and cognitive empathy, and $r=0.356$ for affective empathy and cognitive empathy. Emergent key themes and subthemes are based on participants' responses. The key themes are heart-touching moments of nurses in providing end-of-life care, challenges encountered by nurses in providing end-of-life care and adaptive strategies used by nurses to the challenges they face in providing end-of-life care. Conclusion: Most nurses during end-of-life care express affective empathy, followed by sympathy and lastly cognitive empathy. Nurses are encouraged to show and practice affective and cognitive empathy rather than using sympathy in caring patient and dealing with family member in the end-of-life situations. Despite the chal-
\end{abstract}


lenges that nurses faced, they are able to provide quality care by utilizing several adaptive strategies such as listening and understanding, showing empathy, providing holistic care, being spiritual and being aware of the role as caregiver.

\section{Keywords}

Sympathy, Empathy, End-of-Life Care, Challenges, Adaptive Strategies

\section{Introduction}

Sympathy and empathy are two concepts that are commonly encountered by nurses who provide end-of-life care. The words shape the thoughts, help determine what is true, and influence the actions while providing care to terminally ill patients. These words can also either instill healing or harm in patients [1].

A nurse providing end-of-life care plays an important role in providing support to both the patient and his/her family during one of their most difficult time. Patients in this stage do not only require physical care but emotional support as well. Aside from being a care provider, nurses should be able to utilize their knowledge in therapeutic communication in order for the patients and his/her family members to verbalize their feelings and concerns. This is very important especially in this stage, as the treatment plan shifts its focus from curative to palliative. Nurses are also expected to become advocates of their patients especially during time that family members and other health care providers have a different decision when it comes to treatment choices. In order to perform these roles, nurses are known to either sympathize or empathize with their patients or his/her family members.

In the $16^{\text {th }}$ century, the term sympathy was used to explain the ability of one individual to attune to the feelings of another. A famous $18^{\text {th }}$ century philosopher named Adam Smith described sympathy as putting oneself in through his imagination in the place of someone else feels how other feels be it joy or sorrow, and thus, enlivening joy and alleviating grief through shared feelings. Nurses express sympathy by speaking to terminally ill patients and their family members to say how sorry he/she is about their situation, patting a patient's family member on the shoulder during difficult time, putting a hand on a patient or family member's arm when they hear the bad news, and dropping the tone of his/her voice when speaking during time that the patient or his/her family members are upset or angry.

On the other hand, empathy is defined as, "the ability to understand and share the feelings of another". It is the ability of someone to put himself in another's shoes and feel what that person is going through and share their emotions and feelings [2]. Empathy can assist doctors to make accurate diagnoses and more caring treatment for their patients [3]. A registered nurse, empathy is a complex emotion and can be a complex concept for nurses as responding with empathy 
requires nurses to be able to put themselves in their patient's shoes, see situations from their perspective and demonstrate that they understand their feelings to confirm they're getting an accurate read. Most importantly, it requires them to act on that understanding in appropriate, therapeutic ways [4].

The purpose of this study is to identify whether nurses project sympathy or empathy while providing end-of-life care. It also aims to determine their lived experiences while proving care at this stage.

\subsection{Sympathy-To Suffer With}

The word sympathy was known to be derived from the ancient Greek word sympáqcia, sympatheia, which literally means "to suffer with" [5]. To express sympathy is to show feeling of care and concern for someone accompanied by a wish to see him better off or happier [6].

Since ancient times, the word sympathy is often used to express how people share someone else's grief or misfortune. At the end of the $16^{\text {th }}$ century the word sympathy was used to explain the ability of a person to accommodate the feelings of another [7].

The first known use of the term sympathy within health care was in a second-century commentary by a Greek physician and philosopher named Galen of Pergamon. In his commentary on Hippocrates' work, he used the term sympathy to describe that affections are transferred from one part of the body to another [8]. One example of showing sympathy is by giving sympathy card to the family of a person who had just passed away.

In health care today, sympathy is now known as a non-therapeutic response by a health care provider as it is believed to be a pity-based response that is often unwelcomed by patients. Most health care providers today are instead trained to express empathy to their patients as it is believed that it is a more objective, scientific and complex construct [5].

\subsection{Empathy-To Put Oneself in the Shoes of Another}

Robert Vischer in 1873 used the German term Einf€uhlung, which literally means "in feeling, in order to define the ability of a person to project the self into another person's situation [9]. In the $20^{\text {th }}$ century with the translation of Freud's works into English, the word empathy was used to denote the word Einf€uhlung. This made a great impact on using the word empathy in $20^{\text {th }}$ century psychoanalytic schools. In 1909, E. B. Titchener defined empathy as the process of feeling or reading ourselves into objects.

Empathy is the ability to acknowledge, understand, and emotionally resonate with a person's feelings and situation, reserving the prosocial desire to help and action aimed at the alleviation of suffering to compassion [5]. Empathy is about recognizing your own biases while genuinely imagining and trying to put yourself in other's shoes. Expressing empathy to others is incredibly difficult to do but it gives a unique perspective that can lead to positive action-taking. An ex- 
ample of empathy is when a health care provider relates himself with the patient because he has been in a similar situation before [10].

There are two types of empathy: cognitive empathy (which is the detached acknowledgement and understanding of a distressing situation based on someone's sense of duty) and affective empathy (which is all of the elements of cognitive empathy plus acknowledgement and understanding of someone's situation by "feeling with" him) [11].

In today's world, empathy is being used by health care providers to engage and empower their patients. As empathy is believed to make patient feel good, valued, and respected [12].

\subsection{The Difference between Sympathy and Empathy}

Compared to sympathy the feeling of empathy is a broader and more intense emotional reaction to a situation someone else's is going through. It is where you take the feelings of a person that you're connecting with. This is the critical difference between the two concepts. In sympathy you are feeling with someone, while in empathy you are feeling for them. Thus, in empathy you are experiencing a portion of someone's emotion and feeling because you see things from their perspective [10].

The ability to empathize is affected by a person's experience of a similar scenario. A person's empathetic qualities can be enhanced if he had experienced living though and struggling though a similar situation as the one he is empathizing with. It also allows them to connect more deeply with the individual as they are going though the same experience.

\subsection{Challenges in Expressing Empathy and How to Overcome Them}

There are different roadblocks to empathy and how to overcome them. The challenges include 1) Not paying attention, 2) Feeling the emotion of the other person but not knowing how or when to communicate empathetically, and 3) Not feeling the same emotion of the other person but knowing intellectually that you need to communicate empathetically [13].

These roadblocks can be solved by 1) Minimizing distractions while talking to the patient, 2) Improving your non-verbal communication skills, 3) Learning more about voice tone, and 4) Knowing that sometimes you can disagree with someone but still understanding what they may be feeling and why.

\subsection{Context of the Research}

A nurse providing end-of-life care plays an important role in providing support to both the patient and his/her family during one of their most difficult times. Patients in this stage do not only require physical care but emotional support as well. Aside from being a care provider, nurses should be able to utilize their knowledge in therapeutic communication for the patients and his/her family 
members to verbalize their feelings and concerns. This is very important specially in this stage, as the treatment plan shifts its focus from curative to palliative. Nurses are also expected to become advocates of their patients especially during time that family members and other health care providers have a different decision when it comes to treatment choices. In order to perform these roles, nurses are known to either sympathize or empathize with their patients or his/her family members. The words (sympathy and empathy) shape the thoughts, help determine what is true, and influence the actions while providing care to terminally ill patients. These words can also either instill healing or harm in patients [1].

But are sympathy and empathy words that every health care provider uses but no one understands being treated dichotomously and conflated on the other. Although the perspectives of health care practitioners and current patients are invaluable source of knowledge in helping differentiate these terms, many nurses still interchange these words while providing palliative care [5]. Hence, one purpose of this study is to identify whether nurses project sympathy or empathy while providing end-of-life care to their patients.

Several challenges faced by health care providers while expressing empathy and how to overcome them. Thus, this study also aims to determine the lived experiences of health care providers particularly nurses while providing end-of-life care [13].

\section{Methodology}

This study utilized the mixed convergent parallel design wherein both the quantitative and qualitative research were employed [14]. It utilized purposive sampling of nurses who experienced providing end-of-life care to patients and their family members. To gather quantitative data, a researcher-made measure of empathy and sympathy was employed. The instrument was adapted from The Adolescent Measure of Empathy and Sympathy (AMES) [15]. The AMES is a valid measure of empathy and sympathy as it balances the emphasis on affective and cognitive empathy, uses clear wordings, and distinguishes between empathy and sympathy. The instrument was revised in this study to specifically determine whether nurses sympathize or empathize with their patients or his/her family members during end-of-life care [15]. To determine the validity of the instrument, a pilot testing was done. The instrument was subjected for review of several experts to validate the content. A five-point scale questionnaire was used by the evaluators. The average rating of the evaluators was computed and compared to the cut-off rating. Likewise, the evaluators' comments and suggestions, and recommendations were considered. The instrument was tested with Cronbach alpha. The gathered quantitative data was triangulated by in-depth interviews and observations. Also, the lived experiences of the nurses while providing end-of-life care and the adaptive measures were determined through these methods. Quantitative data was summarized through Exploratory Factor Analysis 
(EFA). Narratives from interviews was analyzed using the Editing Analysis style in which researchers acted as interpreters who read through texts in search of meaningful segments and once segments were identified and reviewed, the researchers developed a category scheme and corresponding codes that was used to sort and organize the data. The researchers searched for the patterns and structures that connect the thematic categories [16].

\section{Sampling}

The sample is comprised of two hundred three (203) nurses who are working in intensive care units (ICU's) of hospitals and other palliative care settings in Jeddah, Saudi Arabia. There were fifty-two (52) male nurses and one hundred fifty-one (151) female nurses. No age and years of hospital experience criteria were applied.

\section{Results and Findings}

\subsection{What Do Nurses Project While Providing End-of-Life Care-Sympathy or Empathy?}

Table 1 shows the descriptive statistics of the items in the tool for measuring empathy/sympathy:

The KMO measure of sampling adequacy and Barlett's test of sphericity to

Table 1. Descriptive statistics of the items in tool for measuring empathy/sympathy.

\begin{tabular}{|c|c|c|c|}
\hline \multicolumn{4}{|l|}{ Descriptive Statistics } \\
\hline & Mean & $\begin{array}{l}\text { Std. } \\
\text { Deviation }\end{array}$ & $\begin{array}{l}\text { Analysis } \\
\mathrm{N}\end{array}$ \\
\hline When a patient or his/her relative is anxious, I become anxious too & 2.27 & 1.152 & 203 \\
\hline When a patient or his/her relative is angry, I feel angry too & 2.36 & 1.158 & 203 \\
\hline When a patient or his/her relative is scared, I feel afraid & 2.69 & 1.163 & 203 \\
\hline When a patient or his/her relative is sad, I become sad too & 3.10 & 1.108 & 203 \\
\hline I am concerned for relatives of patients with terminal illness & 4.05 & 0.924 & 203 \\
\hline I feel concerned for patients who have a terminal illness & 4.26 & 0.806 & 203 \\
\hline I am sorry for a patient or his/her relative who feels sad & 3.85 & 0.866 & 203 \\
\hline $\begin{array}{l}\text { I feel sorry for a patient who has just been informed that he/she has a } \\
\text { terminal illness }\end{array}$ & 4.01 & 1.017 & 203 \\
\hline $\begin{array}{l}\text { I can often understand how a patient or his/her relative is feeling } \\
\text { even before he/she tells me }\end{array}$ & 4.05 & 0.676 & 203 \\
\hline $\begin{array}{l}\text { I can tell when a patient or his/her relative acts happy when he/she } \\
\text { actually is not }\end{array}$ & 3.86 & 0.879 & 203 \\
\hline I can easily tell how a patient or his/her relative is feeling & 3.71 & 0.831 & 203 \\
\hline $\begin{array}{l}\text { I can tell when a patient or his/her relative is angry even if he/she } \\
\text { tries to hide it }\end{array}$ & 3.97 & 0.777 & 203 \\
\hline
\end{tabular}


determine if the sample is appropriate for factor analysis was explained in Table 2.

Kaiser-Meyer-Olkin Measure of Sampling Adequacy (KMO-MSA)-This measure varies between 0 and 1, and values closer to 1 are better. A value of.6 is a suggested minimum. This implies that the sample size is appropriate for factors analysis. Kaiser (1974) defines KMO of 0.9 to be marvelous, 0.8 meritorious, 0.7 middling, 0.6 mediocre, and 0.5 and below to be miserable and unacceptable [17]. In this analysis, since KMO-MSA $=0.792$ (meritorious), the sample size is appropriate for factor analysis.

Bartlett's Test of Sphericity-This one tests the null hypothesis that the correlation matrix is an identity matrix. An identity matrix is a matrix in which all of the diagonal elements are 1 and all off-diagonal elements are 0 . If this is true, then all correlation coefficients will be zero. You want to reject this null hypothesis. Since $\mathrm{p}<0.05$, we reject the null hypothesis. Thus, factor analysis is appropriate.

Total Variance Explained-Table 3 shows how much variance is accounted

Table 2. Kaiser-Meyer-Olkin measure of sampling adequacy and Barlett's test of sphericity in determining the appropriateness of sample for factor analysis.

\section{KMO and Bartlett's Test}

Kaiser-Meyer-Olkin Measure of Sampling Adequacy

Table 3. Explanation of how much variance is accounted for each number of factors in the tool for measuring empathy/sympathy.

\begin{tabular}{|c|c|c|c|c|c|c|c|c|c|}
\hline \multicolumn{10}{|c|}{ Total Variance Explained } \\
\hline \multirow{2}{*}{ Component } & \multicolumn{3}{|c|}{ Initial Eigenvalues } & \multicolumn{3}{|c|}{ Extraction Sums of Squared Loadings } & \multicolumn{3}{|c|}{ Rotation Sums of Squared Loadings } \\
\hline & Total & $\%$ of Variance & Cumulative \% & Total & $\%$ of Variance & Cumulative \% & Total & $\%$ of Variance & Cumulative \% \\
\hline 1 & 4.154 & 34.619 & 34.619 & 4.154 & 34.619 & 34.619 & 3.022 & 25.183 & 25.183 \\
\hline 2 & 1.975 & 16.456 & 51.075 & 1.975 & 16.456 & 51.075 & 2.615 & 21.791 & 46.974 \\
\hline 3 & 1.739 & 14.494 & 65.569 & 1.739 & 14.494 & 65.569 & 2.231 & 18.595 & 65.569 \\
\hline 4 & 0.799 & 6.660 & 72.230 & & & & & & \\
\hline 5 & 0.649 & 5.408 & 77.638 & & & & & & \\
\hline 6 & 0.545 & 4.540 & 82.178 & & & & & & \\
\hline 7 & 0.523 & 4.358 & 86.536 & & & & & & \\
\hline 8 & 0.477 & 3.977 & 90.512 & & & & & & \\
\hline 9 & 0.357 & 2.974 & 93.486 & & & & & & \\
\hline 10 & 0.327 & 2.722 & 96.208 & & & & & & \\
\hline 11 & 0.243 & 2.024 & 98.232 & & & & & & \\
\hline 12 & 0.212 & 1.768 & 100.000 & & & & & & \\
\hline
\end{tabular}

Extraction Method: Principal Component Analysis. 
for each number of factors being retained. The Principal Component Analysis is the default extraction method in SPSS. It extracts uncorrelated linear combinations of the variables and gives the first factor the maximum amount of explained variance. All following factors explain smaller and smaller portions of the variance and are all uncorrelated with each other. This method is appropriate when the goal is to reduce the data but is not appropriate when the goal is to identify latent constructs. In determining how many factors will be retained, Kaiser [18] (as cited in Field, 2009 [19]) says that all factors having eigenvalues of greater than 1 are retained. This criterion is based on the idea that eigenvalues associated with a component indicate the substantive importance of that component; it is logical to retain only factors that have large eigenvalues. Specifically, for this analysis, it recommended retaining three factors.

Figure 1 determines the scree plot, which is used to determine the number of factors to retain. Cattell [20] (as cited in Field, 2009 [19]) argued that the cut-off point for selecting factors should be at the point of inflection of this curve. The point of inflection is where the slope of the line changes dramatically. In this analysis, the plot has an "elbow" on the fourth component; thus, three factors will be retained. We are retaining the first three factors on the left of the elbow and not including the elbow itself.

Rotated Component Matrix-Table 4 contains the rotated factor loadings

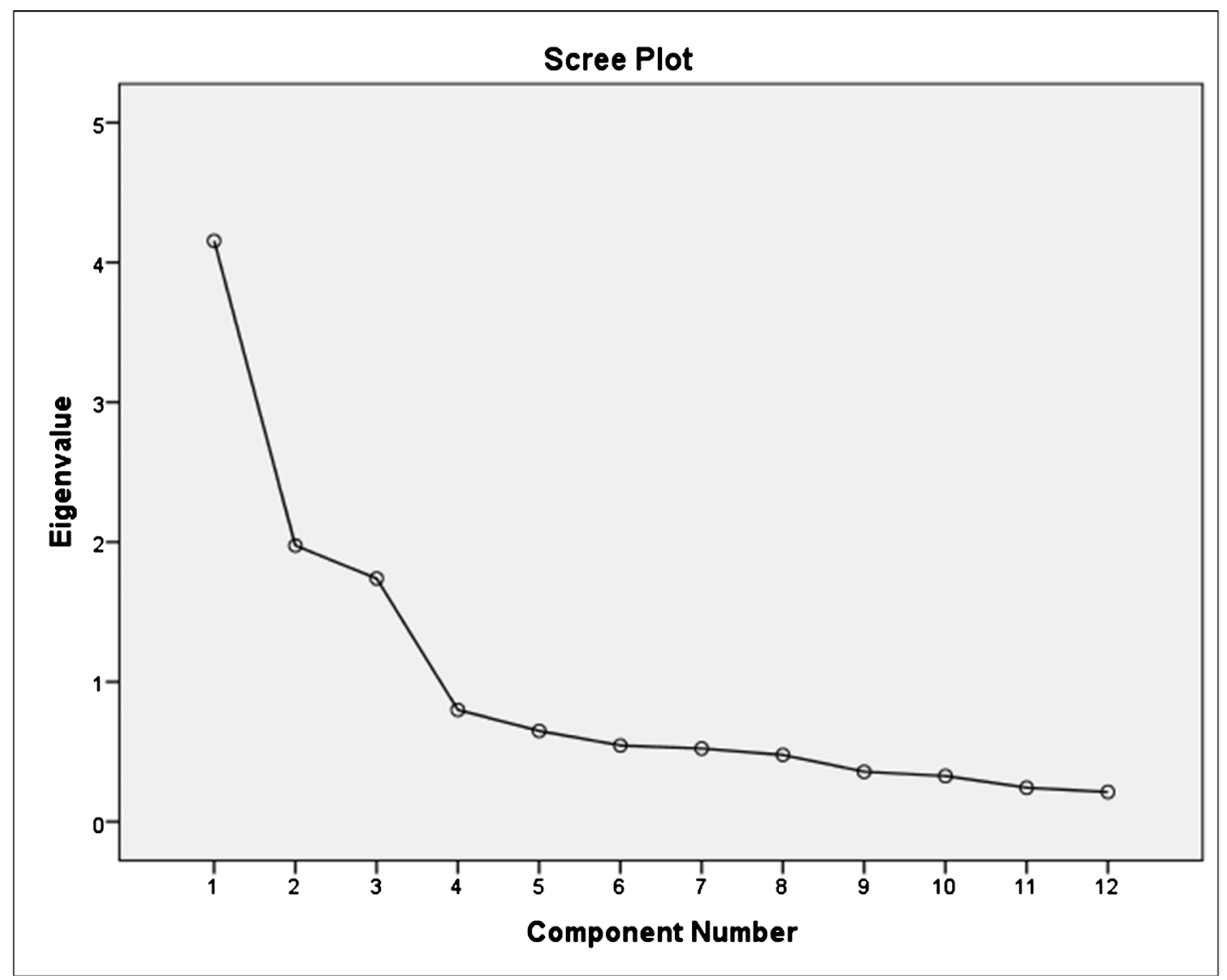

Figure 1. Scree plot showing which factors to retain in the tool for measuring empathy/sympathy. 
(factor pattern matrix), which represent both how the variables are weighted for each factor and the correlation between the variables and the factor. Because these are correlations, possible values range from -1 to +1 . After extracting the factors, SPSS can rotate the factors to better fit the data. Since the factors were expected to be correlated, maximum likelihood extraction method with Promax rotation method was used. Extraction allows determining the number of factors to be retained (either specified or based on eigenvalues). Rotation is defined by Bryant and Yarnold [21] (as cited in Brown, 2009 [22]) as "the procedure in which eigenvalues (factors) are rotated in an attempt to achieve a simple structure". Promax rotation allows the factors to be correlated.

Factor Correlation Matrix-Table 5 contains the Factor Correlation Matrix shows the correlations between the extracted factors.

A factor analysis was conducted on 12 items with maximum likelihood extraction method and oblique (Promax) rotation method. The Kaiser-Meyer-Olkin

Table 4. Rotated component matrix.

\begin{tabular}{|c|c|c|c|}
\hline \multicolumn{4}{|c|}{ Rotated Component Matrix } \\
\hline & \multicolumn{3}{|c|}{ Factor } \\
\hline & 1 & 2 & 3 \\
\hline & Affective Empathy & Sympathy & Cognitive Empathy \\
\hline When a patient or his relative is anxious, $\mathrm{I}$ become anxious too & 0.880 & 0.221 & 0.316 \\
\hline When a patient or his relative is angry, I feel angry too & 0.856 & 0.192 & 0.343 \\
\hline When a patient or his relative is scared, I feel afraid & 0.780 & 0.254 & 0.262 \\
\hline When a patient or his relative is sad, I become sad too & 0.717 & 0.401 & 0.237 \\
\hline I am concerned for relatives of patients with terminal illness & 0.282 & 0.875 & 0.218 \\
\hline I feel concerned for patients who have a terminal illness & 0.045 & 0.714 & 0.196 \\
\hline I am sorry for a patient or his relative who feels sad & 0.315 & 0.710 & 0.243 \\
\hline I feel sorry for a patient who has just been informed that he has a terminal illness & 0.365 & 0.571 & 0.226 \\
\hline I can often understand how a patient or his relative is feeling even before he tells me & 0.285 & 0.315 & 0.718 \\
\hline I can tell when a patient or his relative acts happy when he actually is not & 0.262 & 0.255 & 0.635 \\
\hline I can easily tell how a patient or his relative is feeling & 0.155 & 0.125 & 0.609 \\
\hline I can tell when a patient or his relative is angry even if he tries to hide it & 0.234 & 0.098 & 0.588 \\
\hline
\end{tabular}

Extraction Method: Maximum Likelihood; Rotation Method: Promax with Kaiser Normalization.

Table 5. Factor correlation matrix.

\begin{tabular}{cccc}
\hline \multicolumn{4}{c}{ Factor Correlation Matrix } \\
Factor & 1 & 2 & 3 \\
& Affective Empathy & Sympathy & Cognitive Empathy \\
\hline 1 Affective Empathy & 1.000 & 0.315 & 0.356 \\
2 Sympathy & 0.315 & 1.000 & 0.295 \\
3 Cognitive Empathy & 0.356 & 0.295 & 1.000
\end{tabular}

Extraction Method: Maximum Likelihood; Rotation Method: Promax with Kaiser Normalization. 
$(\mathrm{KMO})$ measure verified the sampling adequacy for the analysis, $\mathrm{KMO}=0.792$ (“meritorious" according to Kaiser (1974)). Bartlett's Test of (Sphericity $\chi^{2}$ (66) $=1007.294, \mathrm{p}<0.001)$ indicates that correlations between items were sufficiently large for factor analysis. An initial analysis was run to obtain eigenvalues for each component/factor in the data. Three components had eigenvalues over the Kaiser's criterion of 1 and in combination explained $65.57 \%$ of the total variance. The scree plot also showed to retain three components. Given the fair sample size and the equivalence of the scree plot and Kaiser's rule on three components, three components will be retained in the final analysis. Table 6 shows the factor loadings after rotation. The items that cluster on the same components suggest that component 1 represents the affective empathy, component 2 characterizes the sympathy, and component 3 the cognitive empathy. The newly formed four-itemed factors were proven to be internally consistent (affective empathy $a$ $=0.881$, sympathy $\alpha=0.804$, and cognitive empathy $\alpha=0.728$ ). Correlations between the factors were $r=0.315$ for affective empathy and sympathy, $r=0.295$ for sympathy and cognitive empathy, and $r=0.356$ for affective empathy and cognitive empathy.

Table 6. Factor loadings of the items of the tool for measuring empathy/sympathy*.

Study Sample $(\mathrm{N}=203)$

Affective Empathy Sympathy Cognitive Empathy

\section{Factor 1: Affective Empathy}

When a patient or his/her relative is anxious, I become anxious too

When a patient or his/her relative is angry, I feel angry too

When a patient or his/her relative is scared, I feel afraid

When a patient or his/her relative is sad, I become sad too
0.880

0.862

0.842

0.758

Factor 2: Sympathy

I am concerned for relatives of patients with terminal illness

0.860

I feel concerned for patients who have a terminal illness

0.811

I am sorry for a patient or his/her relative who feels sad

0.775

I feel sorry for a patient who has just been informed that he/she has a terminal illness

0.660

\section{Factor 3: Cognitive Empathy}

I can often understand how a patient or his/her relative is feeling even before he/she tells me

I can tell when a patient or his/her relative acts happy when he/she actually is not

I can easily tell how a patient or his/her relative is feeling

I can tell when a patient or his/her relative is angry even if he/she tries to hide it

${ }^{*}$ Factor loadings below \pm 0.40 are not shown in the table. 


\subsection{Lived Experiences of Nurses in Providing End-of-Life Care}

Emergent key themes and subthemes based on participants responses. The key themes are heart-touching moments of nurses in providing end-of-life care, challenges encountered by nurses in providing end-of-life care and adaptive strategies used by nurses to the challenges they face in providing end-of-life care.

\section{Discussion}

\subsection{What Do Nurses Project While Providing End-of-Life Care-Sympathy or Empathy?}

The findings show that most nurses during end-of-life care express affective empathy, followed by sympathy and lastly cognitive empathy. Even though nurses are encouraged and trained to practice affective and cognitive empathy, some nurses are not aware that they express sympathy [5] and should not be used as in health care today as it is now known as a non-therapeutic response by a health care provider as it is believed to be a pity-based response that is often unwelcomed by patients. This also shows that nurses have the tendency to interchange these two words causing confusion as they are not synonymous with each other.

The compared to sympathy the feeling of empathy is a broader and more intense emotional reaction to a situation someone else's is going through. It is where you take the feelings of a person that you're connecting with. This is the critical difference between the two concepts. In sympathy you are feeling with someone, while in empathy you are feeling for them. Thus, in empathy you are experiencing a portion of someone's emotion and feeling because you see things from their perspective [10].

\subsection{Lived Experiences of Nurses in Providing End-of-Life Care}

Key Theme 1: Heart-touching moments of nurses in providing end-of-life care as summarized in Table 7

Nurses play a crucial role in providing end-of-life care to patients. As they perform this role, they sometimes experience heart touching moments. Some of them cannot help themselves to develop an emotional connection and during the time of their patient's passing some had a difficult time accepting the situation. Staff nurses who had relationships with the patients who died, experience the most grief related symptoms [23]. The common grief related symptoms

Table 7. Key Theme 1: Heart-touching moments of nurses in providing end-of-life care.

\begin{tabular}{l} 
Subthemes \\
$\begin{array}{c}\text { Supporting Extracts } \\
\text { Hard to say goodbye "It is hard to say goodbye to someone who touches your heart and soul even for a few days. The moment you perform } \\
\text { post-mortem care and no one is looking at you, you find it hard to conceal the sad emotion and you may let a few tears to } \\
\text { drop. But as a human being, we are all mortal; life is a mystery, and death is a possibility". }\end{array}$ \\
$\begin{array}{c}\text { Expression of gratitude "Conscious and coherent patient repeatedly expressing their gratitude to you for taking good care to them". } \\
\text { pecided to bring the "Some relatives if they heard the doctor/physician said that only palliative care could only be provided; the family } \\
\text { patient home }\end{array}$ \\
\hline
\end{tabular}


include the feeling of sadness, crying, and the thinking about death and its negative impact on their relationships, at home and work.

Another heart touching moment as claimed by the participants is when they felt appreciated by their patients for their handwork. Nurses who feel valued have increased commitment and dedication in the work they do. That it is not about the gift cards and the charms that the nurses receive but rather the authenticity, values and unmistakable good feeling that they feel [24].

Some participants also observed situations where the family of the patient has decided to stop buying medications and instead brought home the patient when the doctor had subjected the patient for palliative care. Patients who die at home experience more peace and that their relatives experience more grief. It also shows that more people preferred to die at home. Her study also found out that $91 \%$ of patients who preferred to die at home are influenced by four factors: the patient's preference, the patient's family members or relatives' preference, receipt of community nursing in their last months of life, receipt of home palliative care in the last three months of life [25].

Key Theme 2: Challenges encountered by nurses in providing end-of-life care as summarized in Table 8

Some participants claimed that they have experienced dealing with demanding relatives of the patient. Some of these relatives even curse and shouts at the nurses and even blames them for the condition of the patient. Usually the cause of pressure from the patient's relatives particularly their controlling behavior is fear, anxiety, and possibly guilt especially if the patient is under the care of the family before his admission. Sometimes the patient's relatives may shift the blame to those who are trying to help such as the nurses [26].

As mentioned above, some participants had a hard time in dealing with the

Table 8. Key Theme 2: Challenges encountered by nurses in providing end-of-life care.

\begin{tabular}{|c|c|}
\hline Subthemes & Supporting Extracts \\
\hline Demanding relatives & $\begin{array}{l}\text { - "Sometimes they (patient relatives) demand a lot of services from you that as if you are not doing your job". } \\
\text { "One of the major challenges I have encountered is the pressure from the relatives. They wanted all procedure } \\
\text { to be done in a short period of time and without pain as much as possible. As a nurse you have to meet all the } \\
\text { expectations of the patients and the relatives". }\end{array}$ \\
\hline Curses and shouts at nurses & $\begin{array}{l}\text { - "...cursing the nurses when they feel they are not satisfied with how you serve their patients". } \\
\text { - "....shouts and screams at the staffs when their patient suddenly or already arrested". }\end{array}$ \\
\hline Blaming the nurse & $\begin{array}{l}\text { - "The challenges I experienced if they could hardly accept the fact, the family and patient is in denial and keep } \\
\text { on blaming somebody". }\end{array}$ \\
\hline Feeling emotional & $\begin{array}{l}\text { - "...cries literally on your shoulder when they feel that their patient is slowly regressing". } \\
\text { - "One of the few challenges I have encountered when dealing with the patient and their relatives is to be strong } \\
\text { and not to show off any signs of pity to both the patient and the relatives. It is hard to see someone, whether } \\
\text { related to you or not, to be on the verge of dying. It is hard to keep the emotion of loneliness to see someone } \\
\text { battling for his own life. Being in contact with the patient makes the sorrow and the pain indirectly connected to } \\
\text { you and remaining strong and numb to the situation makes life challenging". }\end{array}$ \\
\hline $\begin{array}{l}\text { Seeing the face of your late } \\
\text { loved ones on the patient }\end{array}$ & $\begin{array}{l}\text { - "There are times that you may see the faces of your late loved ones who also suffered the same condition as your } \\
\text { patient". }\end{array}$ \\
\hline
\end{tabular}


loss of their patients and this can also cause a challenge in providing end-of-life care. Some participants even claim that they see the face of their departed love one on their patients' faces. This shows that some of the participants might have developed countertransference. Countertransference is the nurses' emotional attachment to his/her patient. Nurses can be emotionally attached to patient as long as they follow professional boundaries. These actually allow them to connect more deeply with the individual especially they are going through the same experience.

Key Theme 3: Adaptive strategies used by nurses to the challenges they face in providing end-of-life care as summarized in Table 9

As the participants experience several challenges in providing end-of-life care, most of them were able to use adaptive strategies to overcome them. Several adaptive strategies used include carefully listening and understanding and empathizing with the patient.

There are Different roadblocks to empathy and how to overcome them. The challenges include 1) Not paying attention, 2) Feeling the emotion of the other person but not knowing how or when to communicate empathetically, and 3) Not feeling the same emotion of the other person but knowing intellectually that you need to communicate empathetically [13].

These roadblocks can be solved by 1) Minimizing distractions while talking to the patient, 2) Improving your non-verbal communication skills, 3) Learning more about voice tone, and 4) Knowing that sometimes you can disagree with someone but still understanding what they may be feeling and why.

While some of the participants adapt to the challenges in providing end-of-life

Table 9. Key Theme 3: Adaptive strategies used by nurses to the challenges they face in providing end-of-life care.

\begin{tabular}{|c|c|}
\hline Subthemes & Supporting Extracts \\
\hline Listen and understand & $\begin{array}{l}\text { - "All people who undergo/experiences that situation go through the process of grief. The best thing we } \\
\text { could do as nurses during the phases is to listen, understand their feelings and have empathy with } \\
\text { them". } \\
\text { - "...nurses should be sensitive and give more understanding". } \\
\text { - "... be sensitive with their feelings, let them show their emotions and listening with them". }\end{array}$ \\
\hline Showing empathy & - "...they are demanding in some ways and you need to understand them by showing empathy". \\
\hline Providing holistic care & $\begin{array}{l}\text { - "In dealing with patients when providing end-of-life care, I usually provide extra care and attention to } \\
\text { them without compromising the nursing care for other patients. It is goal oriented and } \\
\text { patient-and-family centered because as a nurse you must deliver nursing care in a holistic approach". } \\
\text { "Another measure I used to employ is serving my patient holistically. All life aspects is always } \\
\text { considered in the delivery of care so I make sure that everything that my patient needs would be given so } \\
\text { that if then that life is not anymore possible for him/her at least in my hands he/she have died a dignified } \\
\text { death". }\end{array}$ \\
\hline Being spiritual & $\begin{array}{l}\text { - "The adaptive measure I utilized in overcoming these challenges is being spiritual. I pray and offer to the } \\
\text { Lord whatever fate my patient would have and pray that the family would be able to accept the possible } \\
\text { outcome that their patient might end". }\end{array}$ \\
\hline Being aware of the role as caregiver & $\begin{array}{l}\text { - “...by maintaining professional boundaries with patients and relatives and being aware of my role as a } \\
\text { health care provider". }\end{array}$ \\
\hline
\end{tabular}


care by providing holistic nursing care. Holistic Nursing is defined as "all nursing practice that has healing the whole person as its goal" [27]. This means that the nurse should consider the physical, emotional, psychological, spiritual, and social aspects of her patient when developing a care plan. Through holistic care, the nurse becomes fully aware of the patient's strengths and weaknesses in all of the patient's aspects as mentioned above and this leads to individualized and complete care for the patients. Holistic nursing care is believed to facilitate healing and has its origins to the care provided by Florence Nightingale [27].

Another adaptive strategy that was utilized is the nurse being spiritual. One participant said that he prays and offers to God the fate of her patient and that the family would be able to accept the possible outcome that their patient might end. A study conducted shows that most patient appreciates receiving prayers from their nurses [28]. Although nurses' experiences with prayer may vary from one another, they personally pray for patients as well as their own needs such as asking for spiritual strength so they can provide better and richer support to patients and their families [29].

Some participants cope up with the challenges they face in providing end-of-life care by maintaining professional boundaries with patients and relatives and being aware of their role as a health care provider. Professional boundaries are very important as it separates the therapeutic behavior of the nurse from any behavior that could reduce the benefit of care to clients. These boundaries are the limitations to the relationship of a nurse and their client which allow for a safe, therapeutic connection between them [30].

\section{Conclusion}

It seems evident that from these findings, most nurses during end-of-life care express affective empathy, followed by sympathy and lastly cognitive empathy. Nurses are encouraged to show and practice affective and cognitive empathy rather than using sympathy in caring patient and dealing with family member in the end-of-life situations. The findings also reveal that the lived experiences of nurses in providing end-of-life care vary from one another. Some nurses had experienced heart-touching moments with their patients, while some felt challenged. Despite the challenges that nurses faced, they are able to provide quality care by utilizing several adaptive strategies such as listening and understanding, showing empathy, providing holistic care, being spiritual and being aware of the role as caregiver. It is therefore recommended that nurses should undergo additional training or awareness program on the difference between empathy and sympathy. The findings of this study can also be utilized to develop programs that would further improve the end-of-life care provided by nurses.

\section{Conflicts of Interest}

The author declares no conflicts of interest regarding the publication of this paper. 


\section{References}

[1] Gerdes, K.E. (2011) Empathy, Sympathy, and Pity: 21st-Century Definitions and Implications for Practice and Research.

https://www.tandfonline.com/doi/abs/10.1080/01488376.2011.564027

[2] Stone, J. (2018) The Importance of Empathy in Healthcare.

http://blog.medicalgps.com/the-importance-of-empathy-in-healthcare/

[3] Riess, H. (2014) Center for Building a Culture of Empathy. http://cultureofempathy.com/References/Experts/Others/Helen-Riess.htm

[4] Aubin, B. (2017) The Importance of Empathy in Nurses and Caregivers. https://blog.amplionalert.com/importance-of-empathy-nurses-caregivers

[5] Soto-Rubio, A. (2018) In Defense of Sympathy, in Consideration of Empathy, and in Praise of Compassion: A History of the Present. https://www.jpsmjournal.com/article/S0885-3924(17)31241-1/abstract

[6] Burton, N. (2018) Empathy vs. Sympathy. Sympathy and Empathy Often Lead to Each Other, but Not Always.

https://www.psychologytoday.com/us/blog/hide-and-seek/201505/empathy-vs-sym pathy

[7] Hanley, R.P. (2015) The Eighteenth-Century Context of Sympathy from Spinoza to Kant. In: Schliesser, E,, Ed., Sympathy. A History, Oxford University Press, New York. https://doi.org/10.1093/acprof:oso/9780199928873.003.0010

[8] Holmes, B. (2015) Reflexion Galen's Sympathy. In: Schliesser, E., Ed., Sympathy. A History, Oxford University Press, New York.

[9] Mallgrave, H. (1994) Empathy, Form, and Space: Problems in German.

[10] Kramer, B. (2018) The Critical Difference between Sympathy and Empathy. https://www.forbes.com/sites/forbescoachescouncil/2018/08/13/the-critical-differen ce-between-sympathy-and-empathy/\#7fac5a1016a3

[11] Fishcel, J.E. (2014) Routine, Empathic and Compassionate Patient Care: Definitions, Development, Obstacles, Education and Beneficiaries. Journal of Evaluation in Clinical Practice, 20, 872-880

[12] Ficarra, B. (2018) How Empathy Can Help Empower Patients. https://www.huffingtonpost.com/barbara-ficarra/why-empathy-empowers-pati_b_7 83138.html

[13] Swink, D. (2018) I Don't Feel Your Pain: Overcoming Roadblocks to Empathy. https://www.psychologytoday.com/us/blog/threat-management/201303/i-dont-feelyour-pain-overcoming-roadblocks-empathy

[14] Creswell, J.W. (2011) Best Practices for Mixed Methods Research in the Health Sciences.

[15] Vossen, H.G.M., Piotrowski, J.T. and Valkenburg, P.M. (2015) Development and Validation of the Adolescent Measure of Empathy and Sympathy (AMES). Personality and Individual Differences, 74, 66-71. https://doi.org/10.1016/j.paid.2014.09.040

[16] Polit, D.F. and Beck, C.T. (2010) Essentials of Nursing Research: Appraising Evidence for Nursing Practice. 7th Edition, Wolters Kluwer Health/Lippincott Williams \& Wilkins, Philadelphia.

[17] Kaiser, H.F. (1974) An Index of Factorial Simplicity. Psychometrika, 39, 31-36. https://doi.org/10.1007/BF02291575

[18] Kaiser, H.F. (1960) The Application of Electronic Computers to Factor Analysis. 
Educational and Psychological Measurement, 20, 141-151. https://doi.org/10.1177/001316446002000116

[19] Field, A. (2009) Discovering Statistics Using SPSS. 3rd Edition, SAGE Publications, Thousand Oaks, CA.

[20] Cattell, R. (1966) The Scree Test for Number of Factors. Multivariate Behavioral Research, 1, 245-276. https://doi.org/10.1207/s15327906mbr0102_10

[21] Bryant, F.B. and Yarnold, P.R. (1995) Principal Components Analysis and Confirmatory Factor Analysis. In: Grim, L.G. and Yarnold, P.R., Eds., Reading and Understanding Multivariate Statistics, American Psychological Association, Washington DC, 99-136.

[22] Brown, J.D. (2009) Choosing the Right Type of Rotation in PCA and EFA. Shiken: JALT Testing and Evaluation SIG Newsletter, 13, 20-25.

[23] Rickerson, E. (2005) How Well Are We Caring for Caregivers? Prevalence of Grief-Related Symptoms and Need for Bereavement Support among Long-Term Care Staff. Journal of Pain and Symptom Management, 30, 227-233.

[24] Raso, R. (2014) The Importance of Being Appreciated. Nursing Management (Springhouse), 45, 6.

[25] Barbara, G., et al. (2015) Is Dying in Hospital Better than Home in Incurable Cancer and What Factors Influence This? A Population-Based Study. BMC Medicine, 13, 235.

[26] Boudreaux, A. (2010) Keeping Your Cool with Difficult Family Members. Nursing, 40, 48-51.

[27] American Holistic Nurses' Association (2019) Definition of Holistic Nursing. https://www.ahna.org/About-Us/What-is-Holistic-Nursing

[28] Taylor, E.J. and Mamier, I. (2005) Spiritual Care Nursing: What Cancer Patients and Family Caregivers Want. Journal of Advanced Nursing, 49, 260-267. https://doi.org/10.1111/j.1365-2648.2004.03285.x

[29] Kim-Godwin, Y. (2013) Prayer in Clinical Practice: What Does Evidence Support? Journal of Christian Nursing, 30, 208-215. https://doi.org/10.1097/CNJ.0b013e31826c2219

[30] Nursing and Midwifery Board of Australia Code of Professional Conduct for Nurses. https://www.nursingmidwiferyboard.gov.au 